\title{
Nanocrystalline Porous Hydrogen Storage Based on Vanadium and Titanium Nitrides
}

\author{
A. Goncharov, ${ }^{1}$ A. Guglya, ${ }^{1}$ A. Kalchenko, ${ }^{1}$ E. Solopikhina, ${ }^{1}$ V. Vlasov, ${ }^{1}$ and E. Lyubchenko ${ }^{2}$ \\ ${ }^{1}$ National Science Center "Kharkov Institute of Physics and Technology", 1 Akademicheskaya Str., Kharkov 61000, Ukraine \\ ${ }^{2}$ National Technical University "Kharkov Polytechnic Institute”, 21 Kyrpychova Str., Kharkov 61002, Ukraine
}

Correspondence should be addressed to A. Guglya; guglya@kipt.kharkov.ua

Received 19 October 2016; Revised 16 December 2016; Accepted 28 December 2016; Published 24 January 2017

Academic Editor: Li Lu

Copyright (C) 2017 A. Goncharov et al. This is an open access article distributed under the Creative Commons Attribution License, which permits unrestricted use, distribution, and reproduction in any medium, provided the original work is properly cited.

This review summarizes results of our study of the application of ion-beam assisted deposition (IBAD) technology for creation of nanoporous thin-film structures that can absorb more than $6 \mathrm{wt} . \%$ of hydrogen. Data of mathematical modeling are presented highlighting the structure formation and component creation of the films during their deposition at the time of simultaneous bombardment by mixed beam of nitrogen and helium ions with energy of $30 \mathrm{keV}$. Results of high-resolution transmission electron microscopy revealed that $\mathrm{VN}_{x}$ films consist of 150-200 nm particles, boundaries of which contain nanopores of 10-15 nm diameters. Particles themselves consist of randomly oriented 10-20 nm nanograins. Grain boundaries also contain nanopores (3-8 nm). Examination of the absorption characteristics of $\mathrm{VN}_{x}, \mathrm{TiN}_{x}$, and $(\mathrm{V}, \mathrm{Ti}) \mathrm{N}_{x}$ films showed that the amount of absorbed hydrogen depends very little on the chemical composition of films, but it is determined by the structure pore. The amount of absorbed hydrogen at $0.3 \mathrm{MPa}$ and $20^{\circ} \mathrm{C}$ is $6-7 \mathrm{wt} . \%$, whereas the bulk of hydrogen is accumulated in the grain boundaries and pores. Films begin to release hydrogen even at $50^{\circ} \mathrm{C}$, and it is desorbed completely at the temperature range of $50-250^{\circ} \mathrm{C}$. It was found that the electrical resistance of films during the hydrogen desorption increases $10^{4}$ times.

\section{Introduction}

Vanadium and titanium hydrides are deemed to be promising as solid state hydrogen storage. The total mass of stored hydrogen in $\mathrm{VH}_{2}$ approaches value of $2.1 \mathrm{wt} . \%$. $\mathrm{TiH}_{2}$ absorbs 4.0 wt. $\% \mathrm{H}_{2}$. Therefore, the amount of absorbed hydrogen atoms comes to be 11.2 in $\mathrm{VH}_{2}$ and 9.1 in $\mathrm{TiH}_{2}\left(\mathrm{at} / \mathrm{cm}^{3}, \times 10^{22}\right)$. Amounts are essentially higher than, for example, in popular $\mathrm{MgH}_{2}$ hydride $\left(2.5 \mathrm{at} / \mathrm{cm}^{3}, \times 10^{22}\right)[1]$.

$\mathrm{V}-\mathrm{H}$ system includes the following phases: $\alpha$ - solid solution; $\beta-\left(\mathrm{VH}_{0.45}-\mathrm{VH}_{0.95}\right)$ with body-centered tetragonal lattice (bct), and $\gamma-\mathrm{VH}_{2}$ with fcc-lattice (it is unstable at the atmospheric pressure). The $\beta+\gamma$ phase mixture is in the $\mathrm{VH}_{1.0}-\mathrm{VH}_{2.0}$ concentration range.

Absorbed hydrogen atoms in vanadium occupy the tetrahedral sites in $\alpha$ - and $\gamma$ - phases and octahedral sites in $\beta$ phase. Diffusion mobility of hydrogen in bcc metals is much higher than in the fcc and hcp metals. According to [2] the diffusion activation energy in $\alpha-\mathrm{VH}_{x}$ at $x=0.17-0.38$ changes in the range of $0.087 \cdots 0.132 \mathrm{eV} /$ at. $(10 \cdots 15.2 \mathrm{~kJ} / \mathrm{mol})$. In the range of $0.486<x<0.736$, where $\beta$-phase exists, energy is nearly steady, that is, $0.230 \cdots 0.240 \mathrm{eV} /$ at. [3]. Comparing the diffusion activation energy of hydrogen and its solubility it is important to note that the diffusion of hydrogen in vanadium is not a limiting factor that determines the stability of its hydride phase. However, it becomes impossible to accumulate and retain the desired weight fraction of hydrogen at the room temperature and atmospheric pressure, which presents the main problem.

Therefore, in order to meet the U.S. Department of Energy requirements [4] for vanadium hydride (gravimetric capacitance: $>5.4 \mathrm{wt} \%$; hydrogen release temperature range: $\left\langle 85^{\circ} \mathrm{C}\right.$ : the time period required to achieve the maximum hydrogen flux: 4 seconds; the equilibrium pressure: $<0.4 \mathrm{MPa}$ ), it is necessary to solve several challenging problems:

(1) To increase the stability of $\gamma$-phase, that is, to lower the equilibrium pressure of the second plateau in PC-T diagram.

(2) To develop such hydride structure that would ensure high diffusion mobility of hydrogen at its accumulation and, in particular, its release. 
(3) To increase the gravimetric capacity by forming additional traps in hydride structure based on vanadium to retain hydrogen at atmospheric pressure and room temperature.

Additionally, there are three phases in Ti-H system: $\alpha$ solid solution; $\beta$ - $\left(\mathrm{TiH}_{0.5}-\mathrm{TiH}_{0.9}\right)$ with bcc-lattice; and $\delta-\mathrm{TiH}_{2}$ with fcc-lattice. During absorption, hydrogen initially occupies the tetrahedral interstitial sites in titanium. As the $\mathrm{H} / \mathrm{Ti}$ ratio approaches 2 , the transition from $\beta$-phase to $\operatorname{fcc} \delta$-phase takes place.

Diffusion mobility of hydrogen in titanium is much worse than in vanadium; it varies in the range of $0.45 \cdots$ $0.52 \mathrm{eV} /$ atom $(52 \cdots 60 \mathrm{~kJ} / \mathrm{mol})[5,6]$. Therefore, unlike the case with vanadium, it is necessary to reduce the thermodynamic stability of $\delta$-phase in titanium, while paragraphs 2 and 3 set out above for vanadium remain relevant for titanium.

The objective of this review is to justify the principles of efficient solid state hydrogen storage formation and to show, in the case of titanium and vanadium, how to create structures with the desired gravimetric, thermodynamic, and kinetic characteristics.

\section{The Main Principles of the Hydrogen Storage Structure Formation}

Problem 1. There are two solutions to the problem of increasing the stability of $\gamma-\mathrm{VH}_{x}$ phase: one solution will have no changes in crystal structure the hydride and the second will have transition to more close-packed structures. In the first case, the process of alloying of vanadium by metal additives is carried out. The most detailed analysis of the influence of 3D-, 4D-, and 5D-transition metals and some metametals on the absorption characteristics of vanadium hydride was made in [7]. It was shown that these additives mainly influence the value of hydrogen pressure of corresponding plateau in $\mathrm{P}$ C-T (pressure-concentration-temperature) curves. However, the amount increase of the absorbed hydrogen has not been achieved as the maximum concentration corresponded to $\mathrm{VH}_{1.85}$ phase. Stability of the $\delta-\mathrm{TiH}_{2}$ phase can be reduced by titanium alloying [8].

The second option for improving the thermodynamic characteristics of vanadium and titanium hydrides is aimed at forming more "dense" VN fcc-lattice instead of "loose" bccvanadium lattice and TiN fcc-lattice instead of hcp-titanium lattice. The nitrogen-containing complex hydrides $\left(\mathrm{VN}_{x}-\mathrm{H}_{y}\right.$ and $\mathrm{TiN}_{x}-\mathrm{H}_{y}$ ) may be formed by hydrogen absorption at these nitrides.

Problem 2. In order to improve kinetic characteristics of any solid state storage, that is, to increase the hydrogen diffusion mobility, it is necessary to transform the structure as such so that the time of hydrogen absorption would be minimal. A natural approach to this challenge is to create materials with an extensive network of grain boundaries, that is, at this stage of the transition from a polycrystalline to a nanocrystalline structure. Orimo et al. [9] demonstrated that it is possible to improve the hydrogen absorption kinetics in vanadium turning to the nanocrystalline objects. It has been shown that hydrogen diffusion in the films with a grain size of about $10 \mathrm{~nm}$ occurs exclusively along the grain boundaries. Diffusion mobility of hydrogen in such material is exactly the same as in the solid solution.

$\mathrm{VN}_{x}$ and $\mathrm{TiN}_{x}$ nitrides (fcc phases) can be formed using the ion-beam assisted deposition (IBAD) technology [10]. The film structure produced by this method is nanocrystalline. Consequently, the nitride phases are nonstoichiometric compounds, and nanograins contain a large number of additional sites at the locations of nitrogen atoms. According to $[11,12]$, such vacant voids can hold up to 4 hydrogen atoms creating additional traps for them. Additionally, increased concentration of vacancies contributes to an increase of hydrogen diffusivity.

Problem 3. It is clear that the implementation of the first two objectives does not achieve the main goal of increasing the gravimetric capacity of vanadium and titanium hydrides. Therefore, a search for different ways to create a system of additional sites for hydrogen holding is needed. Nanopores of $2-4 \mathrm{~nm}$ in size formed in the nanocrystalline structure of vanadium and titanium nitrides during deposition could become such sites along with the vacancies inside the grains at nitrogen atoms locations. Such pores conjoined by grain boundaries form an open porosity, which can accumulate the molecular hydrogen in large quantities and support its intergranular diffusion.

Thus, the following objectives need to be met in order to form vanadium and titanium based structures that can accumulate hydrogen in adequate quantities and release it at the desired temperature range in a short period of time: increase in the absorption enthalpy, improvement of the kinetics of hydrogen desorption, and increase in the absorption capacity. Creation of the complex nitrogen hydrides is acceptable for increasing the enthalpy of absorbents based on vanadium and titanium. To improve the kinetics, a nanocrystalline structure with minimum grain boundaries size and the most advanced boundary system should be formed. To achieve the gravimetric characteristics improvement, it is necessary to create a nanocrystalline structure, which will have the opportunity to store hydrogen not only in atomic but also in molecular state. That is, the required material should combine nanograin structure and the intergranular porosity.

\section{Ion-Beam Assisted Deposition as the Method of Producing Nanoporous Structures}

It is currently known that production of nanocrystalline thin-film structures requires fulfilling one of the two (or simultaneously both) conditions: the high concentration of gas molecules in vacuum chamber atmosphere and bombardment of the substrate with heavy charged particles during the deposition process (see, e.g., [13]). In the first case, a reactive gas, while adsorbing on the freshly forming film surface, reduces the mobility of grain nuclei and inhibits their coalescence. This process results in the columnar structure grinding and in nucleation of the grains with different textures [14]. At the bombardment of deposited film with heavy 


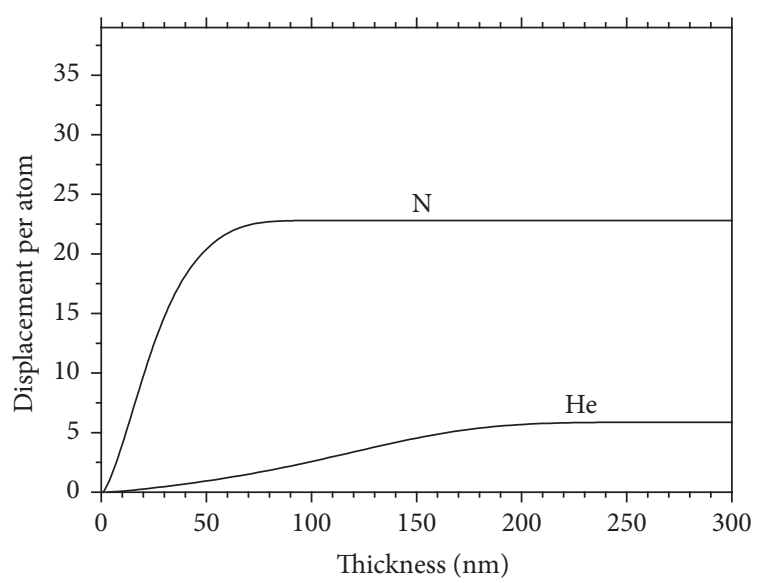

(a)

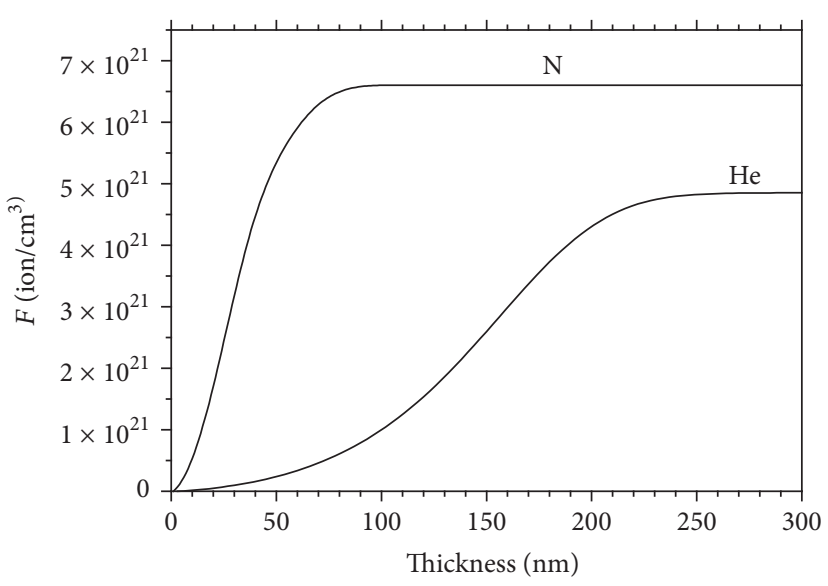

(b)

FIGURE 1: Thickness dependencies of damage distribution (displacement per atom) (a) and implanted helium and nitrogen atoms (b) in the $\mathrm{V}-\mathrm{N}-\mathrm{He}$ film; $U=30 \mathrm{kV}, \mathrm{V} /\left(\mathrm{N}_{2}+\mathrm{He}\right)=0.5 \mathrm{at} / \mathrm{ion}$.

$0.02-2 \mathrm{keV}$ ions, the intensification of diffusion processes on a substrate surface and introduction of the gas ions to a depth of 5-10 nm take place. As a result of this treatment, the film density increases, the grain size decreases, and the columnar structure formation is suppressed $[15,16]$.

However, the best opportunities for the nanocrystalline films formation arise when the substrate in the course of metal vapor deposition is bombarded by gas ions with energies greater than $10 \mathrm{keV}[17,18]$. It is an exact combination of the metal evaporation and irradiation by ions that is realized in IBAD technology. Ions with such energies bombarding the film during its deposition create a large number of defects that become the centers of grain nuclei formation. Consequently, the nanocrystalline structures with grains less than $10 \mathrm{~nm}$ are created $[19,20]$.

The IBAD technology produces both dense and porous nanocrystalline thin-film structures $[19,21]$. It is known that the path depth of ions with an energy of several tens $\mathrm{keV}$ in the solid body crystal lattice is $50-100 \mathrm{~nm}$. This means that during the film growth there is a change of the crystal structure of material at a depth of $50-100 \mathrm{~nm}$ as compared to the structure that formed in its infancy. In particular, there is an increase in the concentration of interstitial gas impurities. By adjusting the ion-beam density, the deposition rate of metal, and the substrate temperature, it can be achieved that the part of gas molecules will condense at the grain boundaries forming the system of gas-filled pores that are preventing the grain boundaries densification. Such pores combined by the grain boundaries create an open pore structure, which can be used for storing hydrogen in large quantities.

The presented overview is a consolidation of findings related to the creation of nanocrystalline porous $\mathrm{VN}_{x}$ and $\mathrm{TiN}_{x}$ thin films and study of their absorption characteristics. The films were prepared by evaporation of the vanadium and titanium from electron-beam crucible at simultaneous irradiation by mixed beam of nitrogen and helium ions with energy of $30 \mathrm{keV}$. The experiments on the hydrogen absorption and desorption were carried out using the purpose made equipment. Examples of preparation and examination techniques were described in the original papers [19-23].

\section{Results and Discussion}

4.1. Structure of $V N_{x}$ Films. The inhomogeneous zone is always observed in the surface layer of deposited film as a result of bombardment by gas ions with energy of several tens keV. Using SPURT program as described previously in [24], we performed a mathematical simulation of the defect formation (Figure 1(a)) and ion implantation of nitrogen and helium (Figure 1(b)) in deposited vanadium films. The number of generated defects and implanted gas concentration are increased successively deep inside of the zone starting from the film surface. The extent of this zone is determined by the path depth of ions used for the bombardment of deposited material. At the given experimental conditions, the width of the inhomogeneous growth stage is up to $250 \mathrm{~nm}$.

Analysis of dependencies (Figure 1) shows that there is a steady increase of the number of created defects and an increase of the concentration of implanted ions at this stage. Most of the damage in the film at the thickness $<80 \mathrm{~nm}$ arises from the nitrogen ions. The extent of damage at the thickness of more than $80 \mathrm{~nm}$ increases slightly exclusively due to the helium ions. The quantity of implanted nitrogen at the thickness of $>80 \mathrm{~nm}$ is $6.5 \cdot 10^{21}$ ions $/ \mathrm{cm}^{3}$, and helium concentration at the thickness of $>250 \mathrm{~nm}$ is $4.8 \cdot 10^{21}$ ions $/ \mathrm{cm}^{3}$. Thus, calculations show that the structure and composition of the film of less than $80 \mathrm{~nm}$ thicknesses can be determined by the concentration of implanted nitrogen ions and number of radiation defects generated by these ions. In the thickness range of $80-250 \mathrm{~nm}$, the film structure can be transformed due to implanting helium ions. Total estimated amount of nitrogen and helium in the vanadium film of thickness $>250 \mathrm{~nm}$ should not exceed 12.0 at. $\%$.

Our electron microscope studies [20-22, 25] of $\mathrm{VN}_{x}$ films structure at the inhomogeneous phase of their growth 


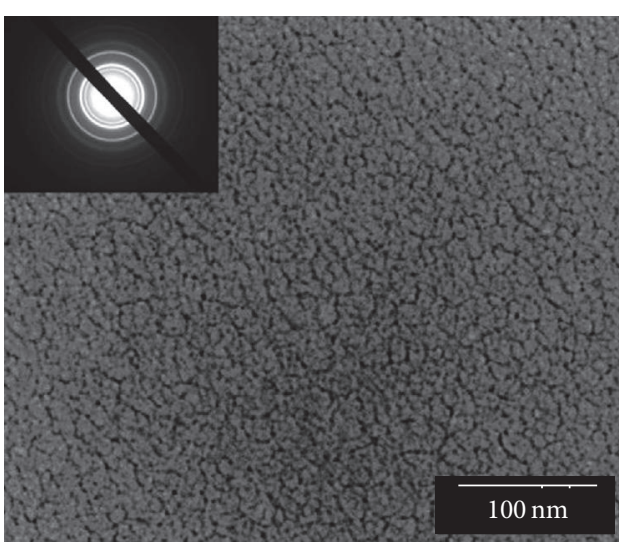

$5 \mathrm{~nm}$

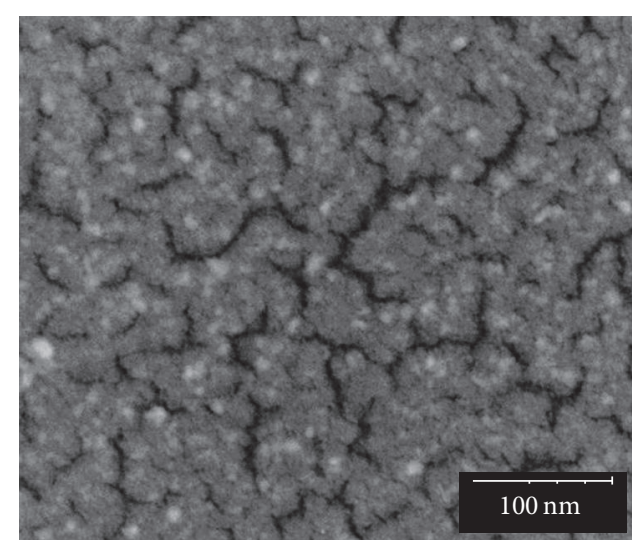

$20 \mathrm{~nm}$

FIGURE 2: Electron microscopy images of the structure of $\mathrm{VN}_{x}$ films at different deposition stages. The given film thicknesses are all estimated values. The figures present the negative images for better visualization of the grain boundaries and pores.

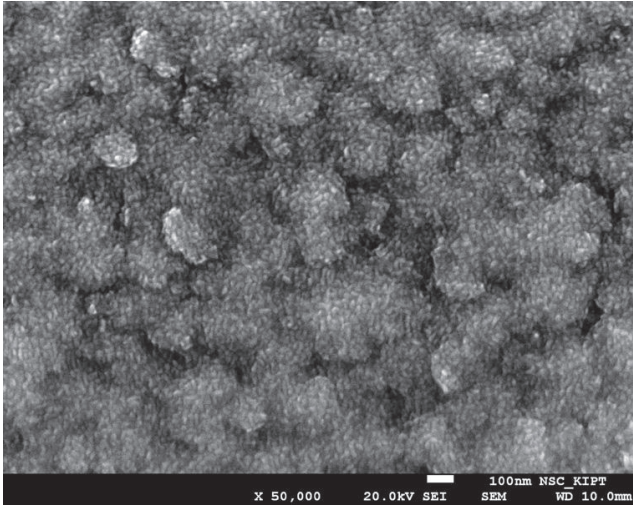

(a)

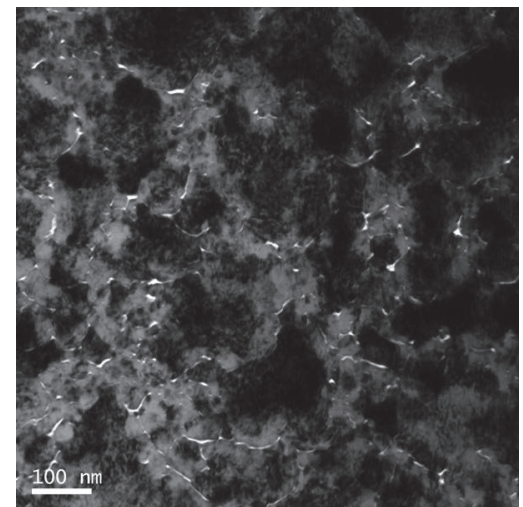

(b)

FIGURE 3: The structure of the surface (a) and particles and interparticle boundaries (b) of already formed $\mathrm{VN}_{x}$ film.

(thickness of 5-50 $\mathrm{nm}$ ) revealed that they are continuous even at the thickness of $5 \mathrm{~nm}$ and have a nanocrystalline structure with grain size of $10-15 \mathrm{~nm}$. The grains are arranged in a single layer; $3-5 \mathrm{~nm}$ pores are observed almost in all triple and quadruple intergranular joints (Figure 2).

Specific ruptures of $100 \mathrm{~nm}$ length and $~ 10-15 \mathrm{~nm}$ width appear in films starting from the thicknesses of $15 \mathrm{~nm}$ and there are large $(\sim 50-150 \mathrm{~nm})$ areas (hereinafter referred to as particles) that are visible between the adjacent ruptures. Particles display heterogeneous structures and consist of nanograins separated by porous boundaries. Filling the ruptures by the grains of new population takes place simultaneously with the subsequent layers formation. Their average size is approximately the same as the size of the grains inside the particle, namely, $\sim 15-20 \mathrm{~nm}$. At film thicknesses more than $30-40 \mathrm{~nm}$ the ruptures are completely filled with nanograins and formation of subsequent layer of particles and grains begins. The crystal structure of $\mathrm{VN}_{x}$ films at all stages of their formation corresponds to the fcc-structure of vanadium nitride.

Figure 3 shows SEM (a) and TEM (b) images of $\mathrm{VN}_{x}$ films deposited on silicon substrates. In the first case, the electron beam was directed at the film surface. In the second case, the sample was prepared by ion thinning of the end face of the substrate with the deposited film. It can be seen (Figure 3(a)) that film structure consists of particles with a diameter of 150 $250 \mathrm{~nm}$. Particles are nonhomogeneous and consist of grains of irregular shape and size of $10-20 \mathrm{~nm}$ arbitrarily distributed in space.

The results of TEM study shown in Figure 3(b) confirm the SEM investigation data. The particles are not homogeneous formations and consist of nanograins. The boundaries are loose; and the connections of 3-4 particles contain pores of $5-10 \mathrm{~nm}$ in size.

In order to explore the structure and orientation of the individual grains in detail high-resolution TEM (HRTEM) was used. Figure 4(a) shows the area inside a single particle. It can be seen that the particle consists of nanograins of 5-15 nm size. Moreover, the crystallographic planes in each grain are arbitrarily oriented with respect to the film plane.

It is difficult to calculate with high accuracy the interplanar spacings in each individual grain using Figure 4(a). The particle morphology and size distribution were analyzed by transmission electron microscopy (JEOL 2100) that was 


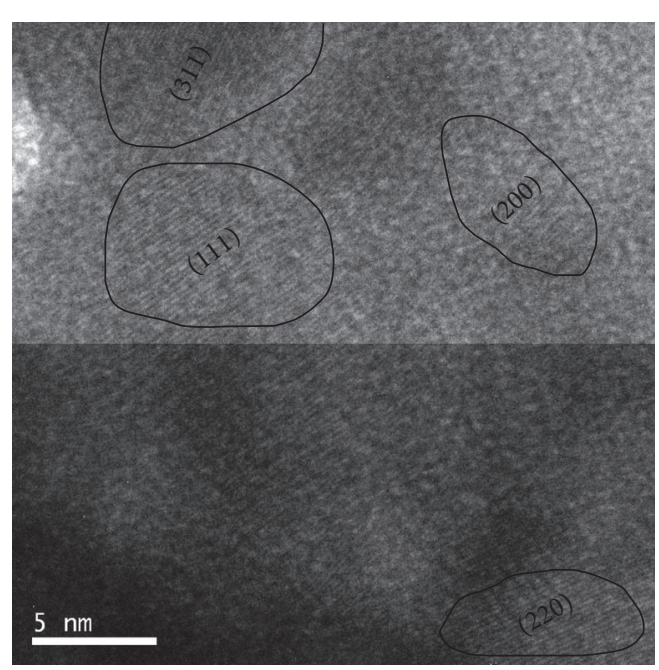

(a)

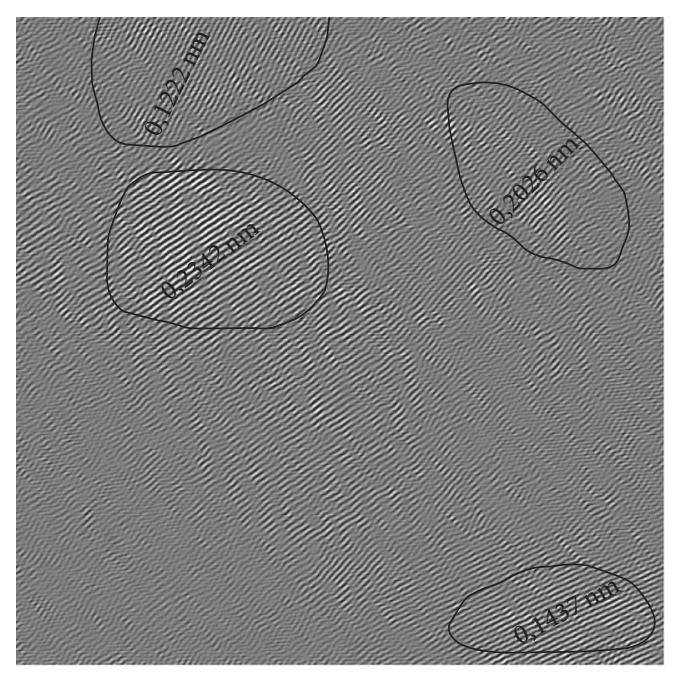

(b)

FIGURE 4: TEM image inside the particle structure of $\mathrm{VN}_{x}$ film (a) and its fast Fourier transform (b).

operated at $200 \mathrm{kV}$. Using the Digital Micrograph Ver. 3.10.0 (Gatan) program, a fast Fourier transform (FFT) pattern of the high-resolution image was obtained. Figure 4(b) demonstrates the results of these investigations. It can be seen that the grains are randomly distributed in the particle volume. Parameter of fcc-crystal lattice of $\mathrm{VN}_{x}$ film calculated on the base of interplanar spacing was $0.4052 \mathrm{~nm}$.

4.2. Absorption/Desorption Processes. We carried out the electron microscopy studies of structural and phase changes in $\mathrm{VN}_{x}-\mathrm{H}_{y}$ films during the hydrogen absorption and desorption. Figure 5 outlines the data of the transmission $(a, b, c)$ and scanning (d, e, f) electron microscopy of $\mathrm{VN}_{x}-\mathrm{H}_{y}$ films of $3 \mu \mathrm{m}$ thickness in their initial state (a, d), after the hydrogen uptake $(b, e)$ and hydrogen desorption $(c, f)$.

It is seen that in their original state the films consist of disordered nonequiaxial particles. The particles of cylindrical shape are of $50-70 \mathrm{~nm}$ in length with bottom diameter of 10 to $15 \mathrm{~nm}$. Due to the fact that the particles are arranged randomly, the bulk of the film contains the pores of an arbitrary shape with the size that is impossible to measure.

Hydrogen-saturated films acquire a round shape and their diameter varies in the range of $30 \cdots 100 \mathrm{~nm}$ (Figure 5(e)). After the hydrogen desorption, the size and shape of the particles are very close to those they have in their initial state. However, it cannot be excluded that some particles merge forming larger objects of irregular shapes. The microdiffraction analysis of initial and hydrogen-saturated films revealed no other phases but the fcc-structure of vanadium nitride. The quantitative microanalysis showed that the content of nitrogen in the original film and in the film after the gas release remains unchangeable, that is, $<3$ at.\%. The $\mathrm{He}$ content in the films estimated using the Rutherford proton backscattering spectra was 1 at.\% or less.

Rutherford backscattering, neutron spectroscopy, and BET (Brunauer, Emmett, Teller) absorption method were used to determine the film porosity, the pore size distributions, and the specific area of the adsorbing surface, respectively.

To determine the film porosity, the procedure proposed in [26] was used. The elemental composition and the film thickness in units of "the number of arbitrary atoms per

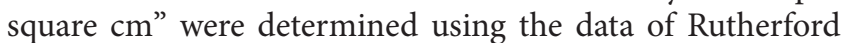
1.8 MeV He ion backscattering spectrometry. In our case, the film thickness $D$ was $2.35 \times 10^{18} \mathrm{arb} . \mathrm{at} / \mathrm{cm}^{2}$. The thickness $d$ of the same film measured using a profilometer was $3 \times 10^{-5} \mathrm{~cm}$. To calculate the film density, the following formula was used [26]:

$$
\rho=\frac{D A}{d}
$$

where $A$ is the mass of the arbitrary film atom in grams and $d$ is the film thickness. If the mass of the arbitrary film atom is $5.51 \times 10^{-23} \mathrm{~g}$, then the calculated film material density according to the formula is $4.3 \mathrm{~g} / \mathrm{cm}^{3}$. Correlating the calculated density with the density of nitrides in the film, we have found that the film material porosity is $27 \pm 3 \%$.

Data obtained in the study of neutron scattering show that there is no fundamental difference between the size distributions of pores for $\mathrm{VN}_{x}$ and $\mathrm{TiN}_{x}$ films [25]. The main group of pores includes pores of 7-14 nm in size; and the small group of pores includes pores of $0.5-5 \mu \mathrm{m}$ in size. There is a small fraction of the pores with sizes greater than $0.5 \mu \mathrm{m}$. Their presence can be explained by some peculiarities of the process of ion stimulated deposition, during which a region with $50-80 \mathrm{~nm}$ thickness always exists in the coating. In this region, the process of the pore formation is not completed and there are cavities with sizes much greater than those in the main material.

The specific area of the adsorbing surface was measured at the temperature of boiling liquid nitrogen $(77 \mathrm{~K})$. Its value was determined using the difference between the pressures 


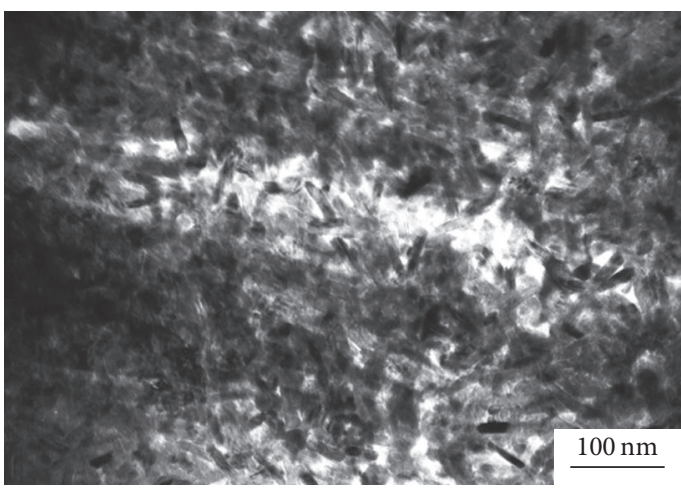

(a)

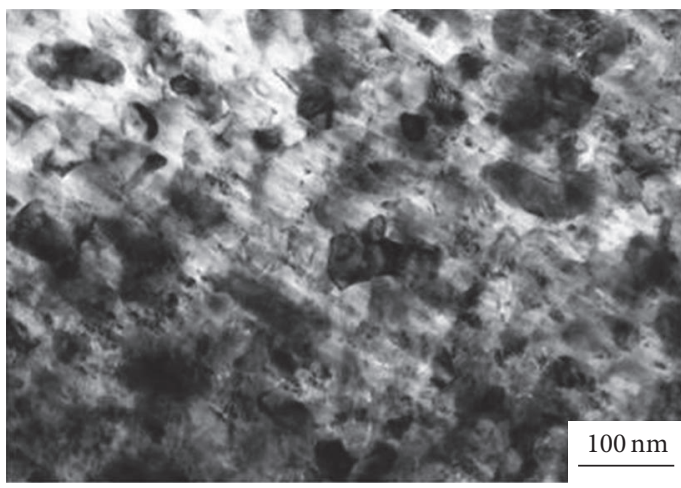

(b)

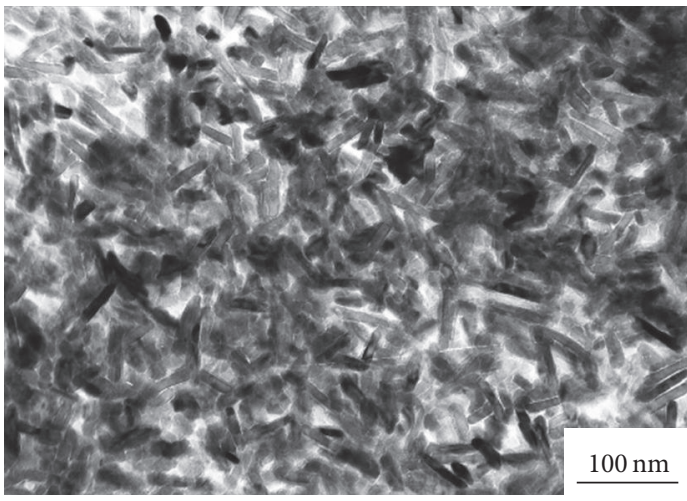

(c)

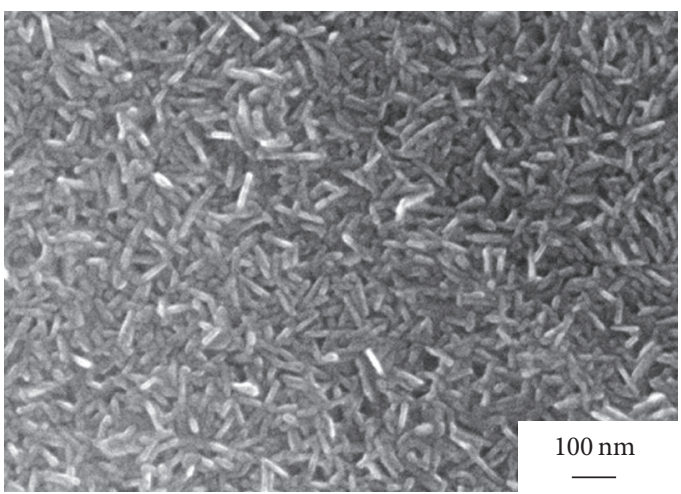

(d)

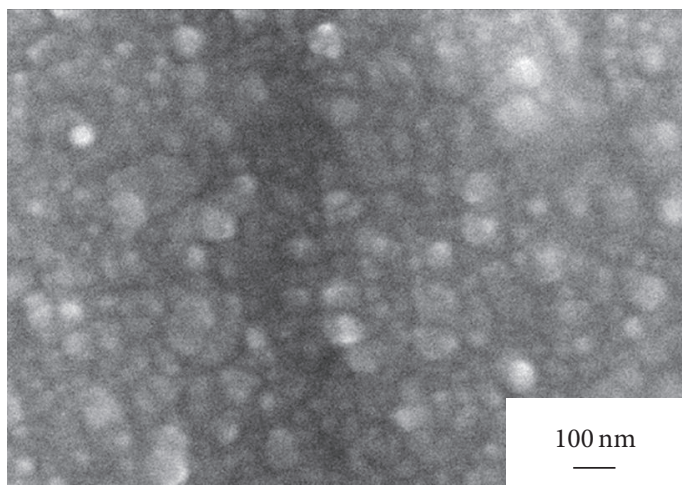

(e)

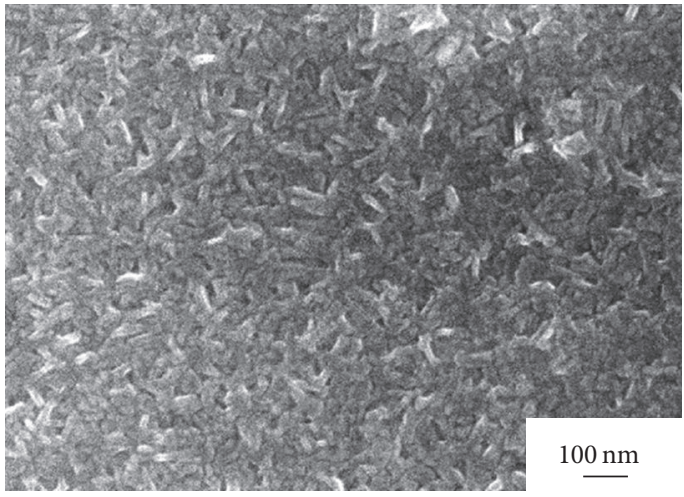

(f)

FIGURE 5: The structure of $\mathrm{VN}_{x}-\mathrm{H}_{y}$ films: (a), (d) original state; (b), (e) hydrogen storage films, and (c), (f) annealed films.

$\Delta P$ at 77 and $293 \mathrm{~K}$. The specific surface measured according to the BET method was $12.4 \mathrm{~m}^{2} / \mathrm{g}$ for $\mathrm{TiN}_{x}$ and $13.2 \mathrm{~m}^{2} / \mathrm{g}$ for $\mathrm{VN}_{x}$.

Hydrogen absorption was evaluated using the volumetric method by plotting absorption isochores and calculating absorption isotherms. Figure 6 shows the results for $\mathrm{VN}_{x}$ and $\mathrm{TiN}_{x}$ films. The data on hydrogen absorption by vanadium and titanium taken from [27-29] are also presented in this figure to compare. Change in the inclination angle of the absorption isochores in the temperature range of $170-250^{\circ} \mathrm{C}$ is observed for both films; the knee of the curve is shifted toward lower temperatures as the amount of hydrogen is increased (Figure 3, [25]). The presence of this knee could be considered as the evidence of the existence of at least two types of porous structures with different absorption heat in tested films. The values of hydrogen absorption are very high in spite of a small specific film surface. The shapes of the hydrogen absorption isotherms are similar for all samples. For the $\mathrm{VN}_{x}$ film at pressures of $0.1-0.125 \mathrm{MPa}$, bends in the curves are observed; they are more visible while the temperature increases. This may be due to the successive filling of traps of various activities by hydrogen and penetration of hydrogen into the grains.

The interpretation of obtained results is difficult because the physical and chemical adsorptions can be involved in the process of hydrogen uptake by $(\mathrm{V}, \mathrm{Ti}) \mathrm{N}_{x}$ films. Physical 


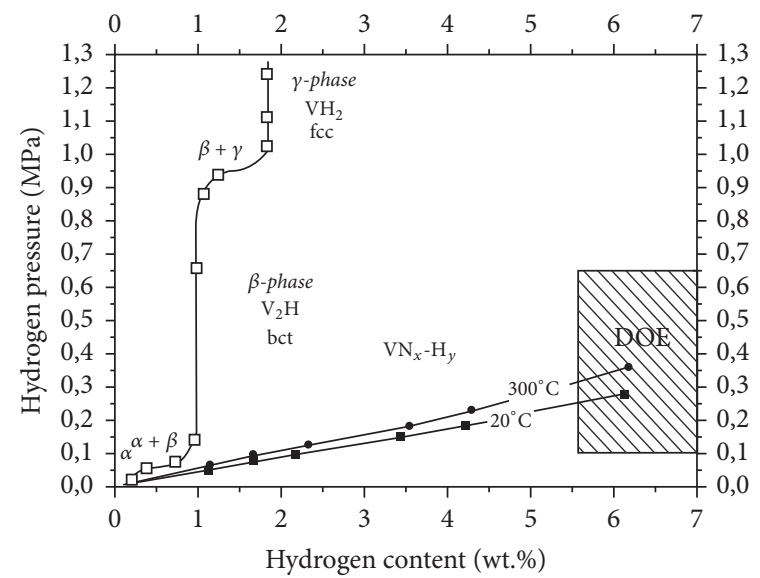

(a)

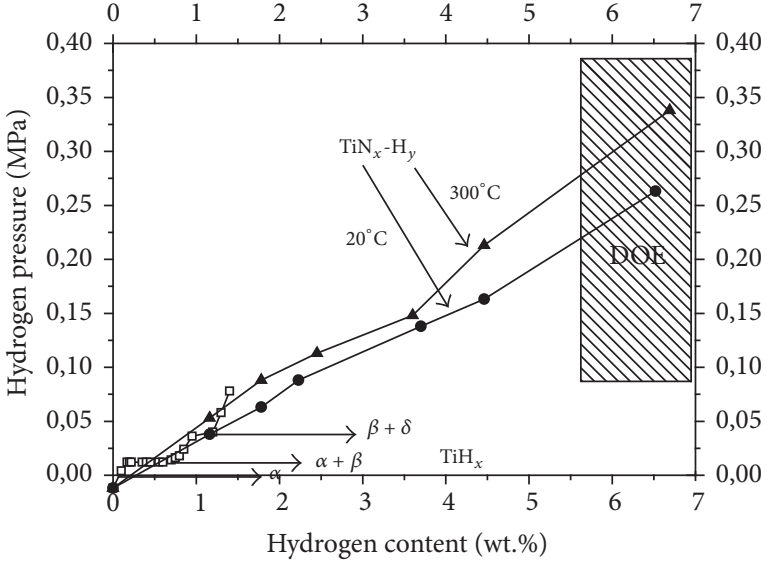

(b)

FIgURE 6: Pressure-concentration dependence for (a) $\mathrm{VN}_{x}-\mathrm{H}_{y}$ and (b) $\mathrm{TiN}_{x}-\mathrm{H}_{y}$ films. Pressure-concentration diagrams for hydride $\mathrm{VH}_{x}$ [27] and $\mathrm{TiH}_{x}[28,29]$.

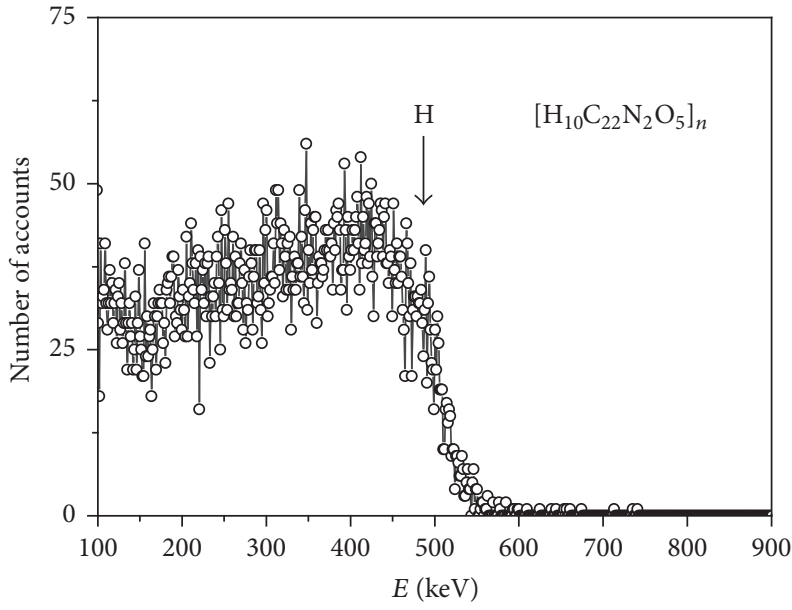

(a)

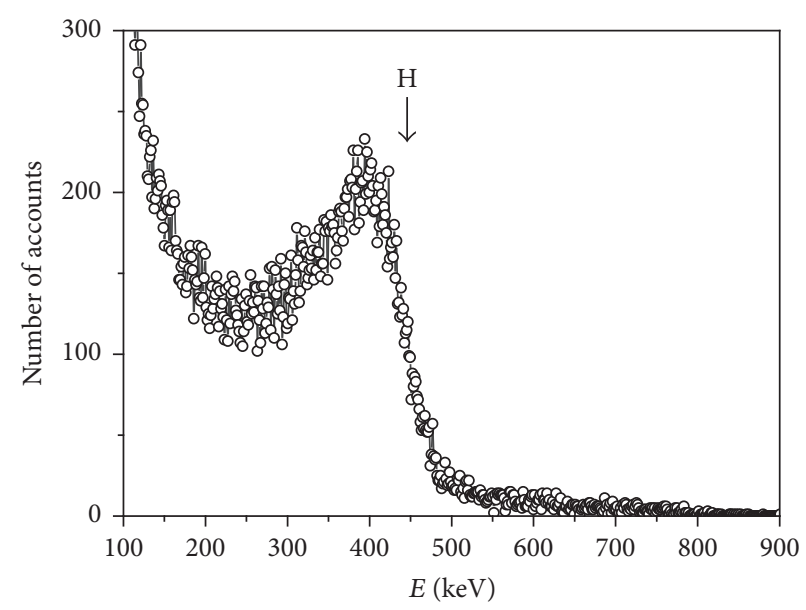

(b)

FIGURE 7: Spectra of knocked out hydrogen nuclei obtained for (a) $\left[\mathrm{H}_{10} \mathrm{C}_{22} \mathrm{~N}_{2} \mathrm{O}_{5}\right]_{n}$ and (b) $\mathrm{VN}_{x}-\mathrm{H}_{y}$ film.

adsorption is related to uptake of hydrogen by porous structures and it decreases usually with an increase in temperature. This dependence is typical for all films; and this fact makes it possible to state that the hydrogen capture occurs mainly in pores. Chemical adsorption can be related to formation of hydrides and amides $\mathrm{MeNH}$ and must become more intense with temperature increase. Vanadium hydride decomposes at $200^{\circ} \mathrm{C}$, and titanium hydride $\mathrm{TiH}_{2}$ is stable in the interval of experimental temperatures [30]. Nevertheless, the isotherms for $\mathrm{VN}_{x}$ and $\mathrm{TiN}_{x}$ films are almost the same confirming the insignificant role of metal-nitrogen hydrides in hydrogen uptake.

In addition to the adsorption method, we used the method of elastic recoil detection to study the absorbing capacity of $\mathrm{VN}_{x}-\mathrm{H}_{y}$ films [31]. A helium ion beam of $1.8 \mathrm{MeV}$ generated by "SOKOL" accelerator was directed at an angle of $15^{\circ}$ to the hydrogen-saturated target. The hydrogen nuclei knocked out of the target were recorded by detector arranged at an angle of $30^{\circ}$ and scattered helium ions were absorbed by Al foil of $7 \mu \mathrm{m}$ thickness, which was placed in front of detector.

The amount of hydrogen contained in the sample was determined by comparing the spectra of knocked out hydrogen nuclei that were obtained for the test specimen and standard sample taking into consideration the slowing-down power. A kapton film $\left(\left[\mathrm{H}_{10} \mathrm{C}_{22} \mathrm{~N}_{2} \mathrm{O}_{5}\right]_{n}\right)$ with hydrogen content 2,64 wt. $\%$ was used as a standard sample. Figure 7 shows the appropriate spectra of knocked out hydrogen nuclei. The measurements showed that the amount of hydrogen in $\mathrm{VN}_{x}$ sample was similar to the sample that was used for the adsorption analysis and was equal to $7.4 \mathrm{wt} . \%$ that confirmed the data from adsorption studies.

Figure 8 (curve 1) shows dependence of the released hydrogen amount from $\mathrm{VN}_{x}$ film on annealing temperature 


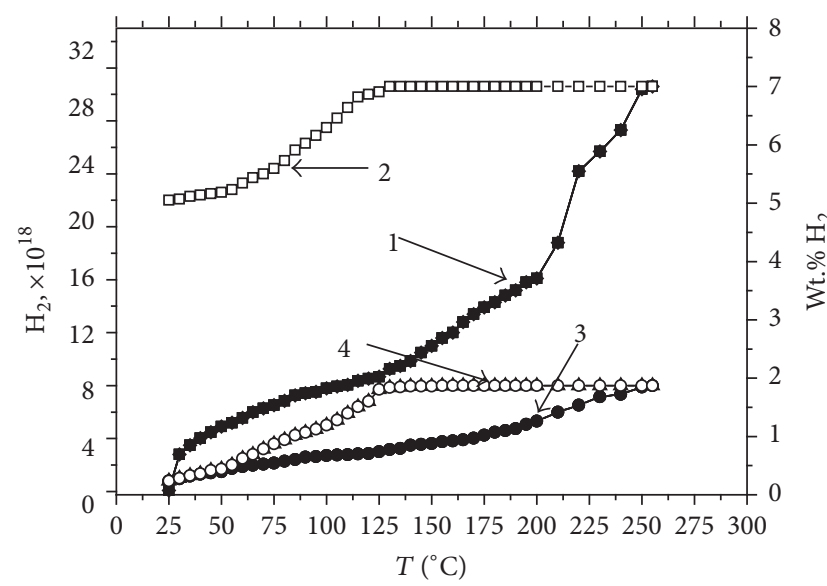

(a)

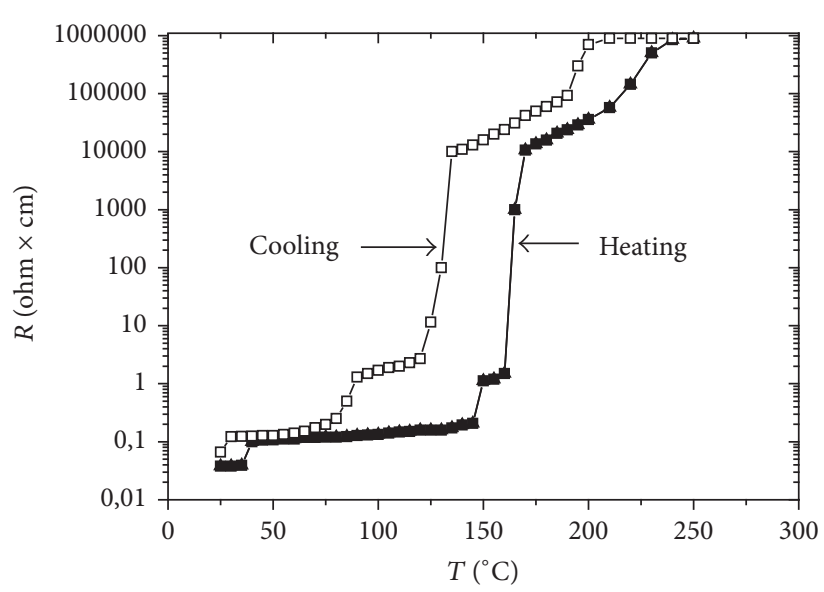

(b)

Figure 8: The relationship of the change in the hydrogen amount in the chamber during heating (1) and cooling (2) of VN $\mathrm{N}_{x}-\mathrm{H}_{y}$ film; the repeated heating (3) and cooling (4) (a). The change in the $\mathrm{VN}_{x}-\mathrm{H}_{y}$ film resistivity during its heating and cooling (b).

(detailed description of hydrogen desorption experiment is in $[22,23])$. It is seen that the hydrogen desorption starts already at $30^{\circ} \mathrm{C}$. The number of molecules of desorbed hydrogen reaches $1.5 \times 10^{19}(3,5 \mathrm{wt} . \%)$ at $200^{\circ} \mathrm{C}$. A further increase in temperature results in a marked increase in hydrogen release rate. At $250^{\circ} \mathrm{C}$ the total mass of released hydrogen exceeds 7 wt.\%. At specimen cooling (curve 2), decrease in pressure inside the working chamber starts at $130^{\circ} \mathrm{C}$ indicating that the portion of released hydrogen is readsorbed by the $\mathrm{VN}_{x}$ film. Total decrease in pressure inside the chamber during cooling to $20^{\circ} \mathrm{C}$ corresponds to the absorption of $8 \cdot 10^{18}$ hydrogen molecules that conforms to $2 \mathrm{wt} . \% \mathrm{H}_{2}$.

To prove this statement we exposed the films to repeated annealing. Figure 8 (curves 3 and 4) shows the change in pressure in annealing chamber during the repeated heating and cooling of films. It can be seen that the amount of released hydrogen is close to the value of $2 \mathrm{wt} . \%$. During the cooling the film reabsorbs hydrogen.

It should be noted that during the repeated cooling of the films (without previous hydrogen saturation) the hydrogen absorption in amount of $2 \mathrm{wt} . \%$ takes place at a total pressure in the chamber not more than $2 \cdot 10^{-1} \mathrm{~mm} \mathrm{Hg}$. The adsorption of hydrogen in such amount at such low pressure indicates that the film surface and the system of intergranular channels and pores have not been "poisoned" by oxygen-containing molecules. At these conditions the absorption of molecular hydrogen by open intergranular porosity can occur at partial hydrogen pressures $2 \cdot 10^{-1} \mathrm{~mm} \mathrm{Hg}$.

Taking into account the structural irregularity of $\mathrm{VN} x$ films, the change of resistivity in absorption and desorption processes can provide the important information about the pores state and kinetics of hydrogen release from them. For multicomponent materials the presence of gas-containing pores in such a structure leads to the appearance of an additional conduction mechanism which is either in the occurrence of thermionic conduction electrons due to emission from the gaseous impurities (nitrogen, oxygen) located on the pore surfaces and/or in their volume or due to the tunnelling effect [32]. Consequently, the resistivity of material with pores filled with gas in whole or in part will be less than that for the material with vacuum pores. In this case the electrical resistivity of material will be determined by the scattering of electrons by phonons and boundaries of nanograins and nanopores.

Figure 8(b) shows the corresponding dependence of $\mathrm{VN}_{x}$ film resistance on annealing temperature. Resistance decrease in the temperature range of 20 to $60^{\circ} \mathrm{C}$ is observed. It is typical for the films with negative temperature coefficient of resistance. Further temperature increase results in rapidly increasing resistance.

At $260^{\circ} \mathrm{C}$ the resistance of $\mathrm{VN}_{x}$ films is $10^{4}$ times greater than the resistance of the hydrogen-saturated samples. Resistance at the cooling remains unchanged leading up to $180^{\circ} \mathrm{C}$ and then decreases. The final value of resistance is $15-20 \%$ lower than resistance of the films saturated with hydrogen.

The increase in resistivity of $\mathrm{VN}_{x}-\mathrm{H}_{y}$ film is correlated with increase of hydrogen desorption (see Figure 8(a)). In our view, it indicates that an increase in annealing temperature results in the complete evacuation of hydrogen from intergranular boundaries and pores. Consequently, the space between grains becomes practically impassable for conductivity electrons, and it leads to dramatic increase in resistivity. At the cooling, the conduction of $\mathrm{VN}_{x}$ film is virtually restored due to the reverse hydrogen absorption from the chamber.

Comparing the curves in Figures 8(a) and 8(b), one can distinguish three temperature ranges: $40-135^{\circ} \mathrm{C}, 135-185^{\circ} \mathrm{C}$, and $185-250^{\circ} \mathrm{C}$, each possessing its own rate of hydrogen desorption and the growth rate of resistance. We assume that the hydrogen evolution in each temperature range occurs from a certain type of traps. At relatively low temperatures $\left(40-135^{\circ} \mathrm{C}\right)$, hydrogen leaves the vacant sites in nanograins moving into the grain boundaries and intergranular pores. At the same time due to the pressure increase in nanopores, the 
hydrogen excess is released from them. The resistivity varies little because the total resistance is mainly dependent on the level of grain boundaries and pores filling by hydrogen.

In the temperature range of $135-185^{\circ} \mathrm{C}$, hydrogen leaves the grain boundaries and nanopores. The electrical resistance of substance in individual particle becomes sufficiently large.

Desorption process ends after the hydrogen is released from interparticle pores and boundaries $\left(185-250^{\circ} \mathrm{C}\right)$. At the same time the resistivity reaches a value more than $10^{5} \Omega \cdot \mathrm{cm}$.

\section{Conclusion}

The results of our studies have shown that $\mathrm{V}$ and Ti deposition at bombardment by high-energy $\mathrm{N}$ and $\mathrm{He}$ ions leads to formation of nanostructured nitrides, in which the intergrain spaces are occupied by pores. The presence of two components in the ion beam, the difference between the distributions of ion energy losses, and the implantation of gas atoms during the process of metal deposition are factors that determine the formation mechanism for material structure and pores. Unlike plasma and thermal deposition, the process of grain nucleation is not finished after the metal condensation and nitride formation; it has the stage of partial destruction of the primary structure with nucleation of the next population of grains, growth of the grains, and formation of a solid film. The progressive filling process of substrate surface leads to formation of cavities in the film volume; they have different hydrogen adsorption capacities and different heats of their adsorption.

Thus, it was shown that the ion-beam assisted deposition technology makes it possible to form composite nanocrystalline structures with disperse nanoporosity. Using this technology, the size of pores and their distribution density play a more significant role than the composition of the film material. The possibility of independent and controlled parameters changing makes it possible to modify purposefully the porosity and composition and thus to produce the materials with different hydrogen adsorption capacities.

\section{Competing Interests}

The authors declare that they have no competing interests.

\section{References}

[1] I. P. Jain, Y. K. Vijay, L. K. Malhotra, and K. S. Uppadhyay, "Hydrogen storage in thin film metal hydride-a review," International Journal of Hydrogen Energy, vol. 13, no. 1, pp. 15-23, 1988.

[2] J. Kleiner, E. Sevilla, and R. Cotts, "Diffusion of hydrogen in 'VHx," Physical Review B, vol. 33, no. 10, pp. 6662-6666, 1986.

[3] Y. Fukai and S. Kazama, "Nmr studies of anomalous diffusion of hydrogen and phase transition in vanadium-hydrogen alloys," Acta Metallurgica, vol. 25, no. 1, pp. 59-70, 1977.

[4] "Targets for on-board hydrogen storage systems: Current R\&D focus is on 2010 Targets," http://wwwl.eere.energy.gov/hydrogenandfuelcells//pdfs/freedomcar_targets_explanations.pdf.

[5] D. N. Williams, "Hydrogen in titanium and titanium alloys," TML Report 100, 1958.
[6] L. C. Covington, "The influence of surface condition and environment on the hydriding of titanium," Corrosion, vol. 35, no. 8, pp. 378-382, 1979.

[7] H. Yukawa, M. Takagi, A. Teshima, and M. Morinaga, "Alloying effects on the stability of vanadium hydrides," Journal of Alloys and Compounds, vol. 330-332, pp. 105-109, 2002.

[8] E. Tal-Gutelmacher and D. Eliezer, "Hydrogen-assisted degradation of titanium based alloys," Materials Transactions, vol. 45, no. 5, pp. 1594-1600, 2004.

[9] S. Orimo, F. Kimmerle, and G. Majer, "Hydrogen in nanostructured vanadium-hydrogen systems," Physical Review B, vol. 63, no. 9, Article ID 094307, 2001.

[10] A. Guglya and I. Marchenko, "Comprehensive guide for nanocoatings technology," in Deposition and Mechanisms: Ion Beam-Assisted Deposition, vol. 1, pp. 45-69, NOVA Press, New York, NY, USA, 2015.

[11] A. Gringoz, N. Glandut, and S. Valette, "Electrochemical hydrogen storage in $\mathrm{TiC}_{0.6}$, not in $\mathrm{TiC}_{0.9}$, Electrochemistry Communications, vol. 11, no. 10, pp. 2044-2047, 2009.

[12] H. Ding, X. Fan, C. Li, X. Liu, D. Jiang, and C. Wang, "Firstprinciples study of hydrogen storage in non-stoichiometric $\mathrm{TiC}_{x}$," Journal of Alloys \& Compounds, vol. 551, pp. 67-71, 2013.

[13] I. Petrov, P. B. Barna, L. Hultman, and J. E. Greene, "Microstructural evolution during film growth," Journal of Vacuum Science and Technology A: Vacuum, Surfaces and Films, vol. 21, no. 5, 2003.

[14] P. B. Barna and M. Adamik, "Fundamental structure forming phenomena of polycrystalline films and the structure zone models," Thin Solid Films, vol. 317, no. 1-2, pp. 27-33, 1998.

[15] J. A. Thornton, "Influence of apparatus geometry and deposition conditions on the structure and topography of thick sputtered coatings," Journal of Vacuum Science \& Technologies, vol. 11, no. 4, pp. 666-670, 1974.

[16] J. E. Greene, S. A. Barnett, J. E. Sundgren, and A. B. Rockett, "Low energy ion/surface interactions during film growth from the vapor phase," in Ion Beam Assisted Film Growth, chapter 5, pp. 101-152, Elsevier, Amsterdam, The Netherlands, 1989.

[17] G. K. Wolf, "Modification of chemical properties of materials by ion beam mixing and ion beam assisted deposition," Journal of Vacuum Science \& Technology A: Vacuum, Surfaces, and Films, vol. 10, no. 4, pp. 1757-1764, 1992.

[18] K. Volz, M. Kiuchi, and W. Ensinger, "Structural investigations of chromium nitride films formed by ion beam-assisted deposition," Surface and Coatings Technology, vol. 108-109, pp. 303-307, 1998.

[19] A. Goncharov, A. Guglya, and E. Melnikova, "On the feasibility of developing hydrogen storages capable of adsorption hydrogen both in its molecular and atomic states," International Journal of Hydrogen Energy, vol. 37, no. 23, pp. 18061-18073, 2012.

[20] V. Bryk, A. Guglya, A. Kalchenko et al., "Hydrogen storage in $\mathrm{VN}_{x}-\mathrm{H}_{y}$ thin films," Open Access Library Journal, vol. 2, no. 12, pp. 1-11, 2015.

[21] V. Bryk, A. Guglya, M. Litvinenko et al., "Mechanisms of nanoporous $\mathrm{VN}-\mathrm{Ar} / \mathrm{He}$ structure formation under high-energy ion bombardment," Radiation Effects and Defects in Solids, vol. 166, no. 4, pp. 282-287, 2011.

[22] A. Guglya, A. Kalchenko, E. Solopikhina, V. Vlasov, and E. Lyubchenko, "Nanocrystalline porous thin film $\mathrm{VN}_{x}$ hydrogen absorbents: method of production, structure and properties," Journal of Advances in Nanomaterials, vol. 1, no. 1, 2016. 
[23] A. Guglya, E. Lyubchenko, Y. Marchenko, E. Solopikhina, and V. Vlasov, "Crystal lattice of solid body can store simultaneously both molecules and atoms of hydrogen in quantities," International Journal of Hydrogen Energy, vol. 41, no. 22, pp. 9410-9417, 2016.

[24] V. I. Bendikov, A. G. Guglya, I. G. Marchenko, D. G. Malykhin, and I. M. Neklyudov, "Mechanisms of forming the $\mathrm{Cr}-\mathrm{N}$ composite in the unsteady-state stage of ion beam-assisted deposition process," Vacuum, vol. 70, no. 2-3, pp. 331-337, 2003.

[25] V. V. Bryk, R. L. Vasilenko, A. V. Goncharov et al., "Formation mechanism, structure and adsorption characteristics of microporous nanocrystalline thin-film (V, Ti)-N-He composites," Journal of Surface Investigation. X-ray, Synchrotron and Neutron Techniques, vol. 5, no. 3, pp. 566-574, 2011.

[26] L. V. Belyakov, T. L. Makarova, V. I. Sakharov, I. T. Serenkov, and O. M. Sreseli, "Composition and porosity of multicomponent structures: porous silicon as a three-component system," Semiconductors, vol. 32, no. 9, pp. 1003-1005, 1998.

[27] K. Papathanassopoulos and H. Wenzl, "Pressure-composition isotherms of hydrogen and deuterium in vanadium films measured with a vibrating quartz microbalance," Journal of Physics F: Metal Physics, vol. 12, no. 7, pp. 1369-1381, 1982.

[28] H. Numakura and M. Koiwa, "Hydride precipitation in titanium," Acta Metallurgica, vol. 32, no. 10, pp. 1799-1807, 1984.

[29] S. R. Peddada, I. M. Robertson, and H. K. Birnbaum, "Hydride precipitation in vapor deposited ti thin films," Journal of Materials Research, vol. 8, no. 2, pp. 291-296, 1993.

[30] A. E. Vol, Handbook of Binary Metallic Systems, 1966.

[31] Y. Wang, "Hydrogen standards in elastic recoil detection analysis," Nuclear Instruments and Methods in Physics Research Section B: Beam Interactions with Materials and Atoms, vol. 219220, pp. 115-124, 2004.

[32] C. A. Neugebauer and M. B. Webb, "Electrical conduction mechanism in ultrathin, evaporated metal films," Journal of Applied Physics, vol. 33, no. 1, 1962. 

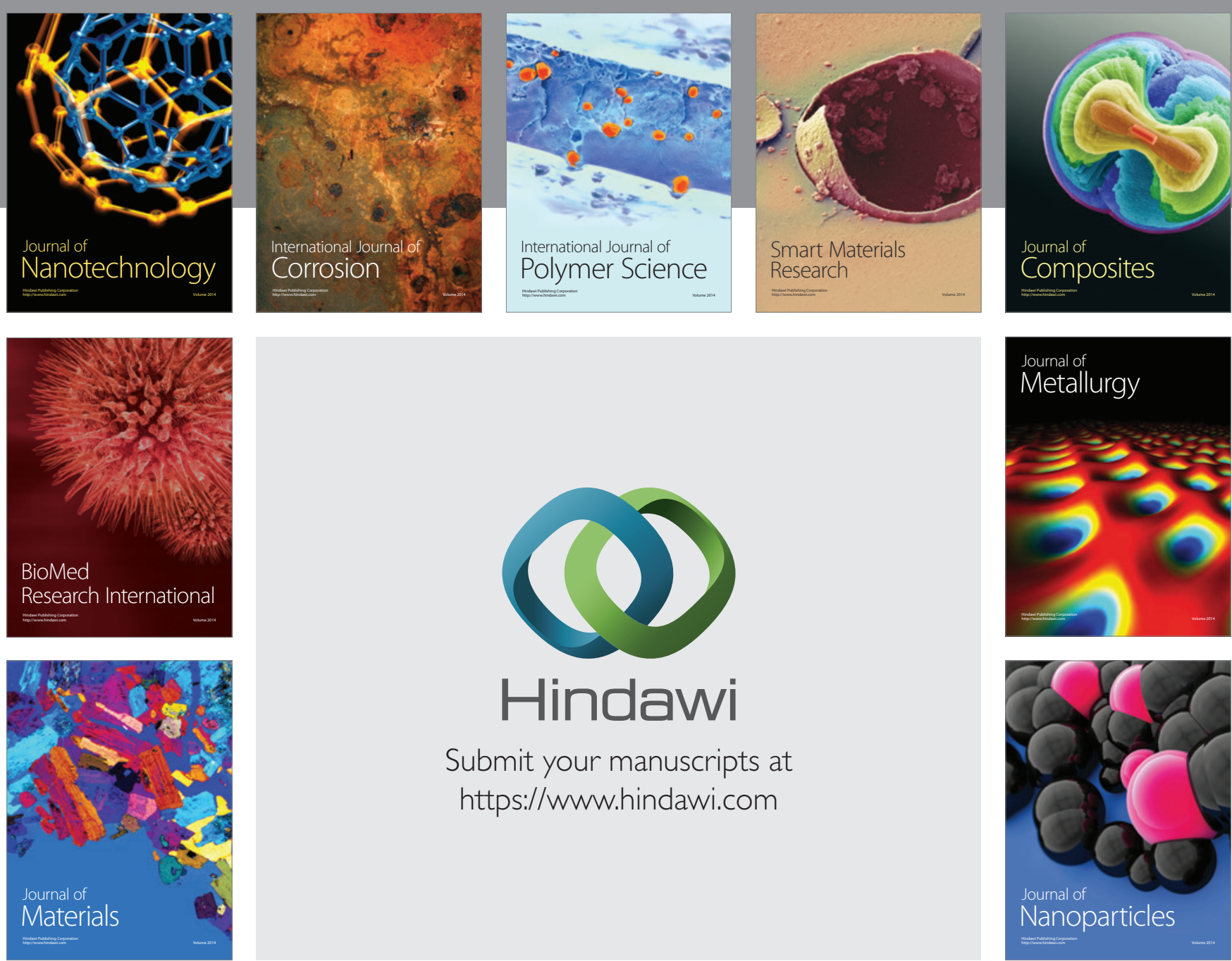

\section{Hindawi}

Submit your manuscripts at

https://www.hindawi.com

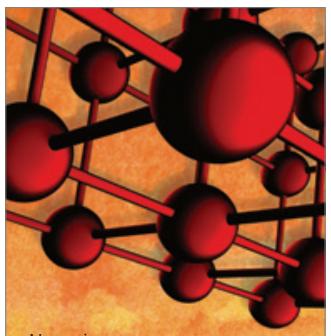

Materials Science and Engineering
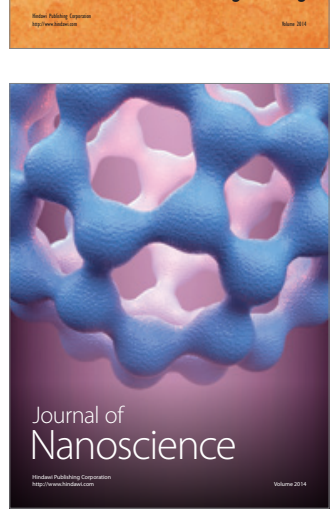
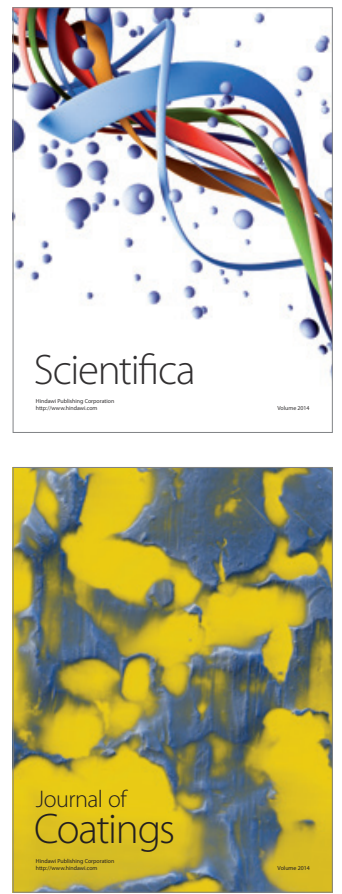
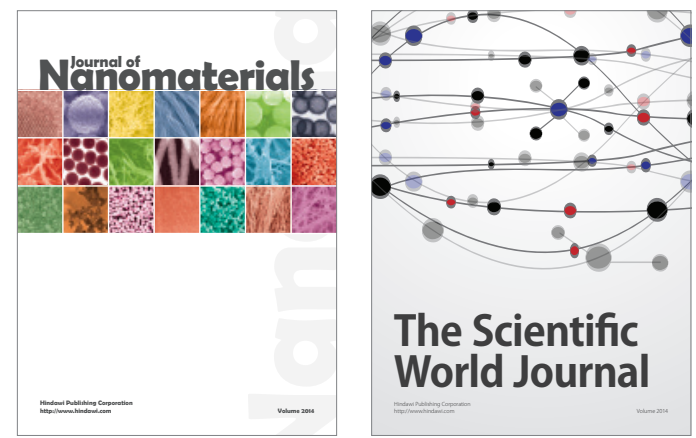

The Scientific World Journal
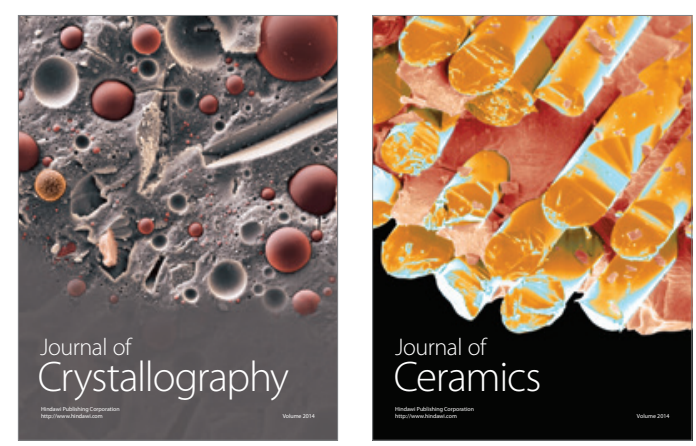
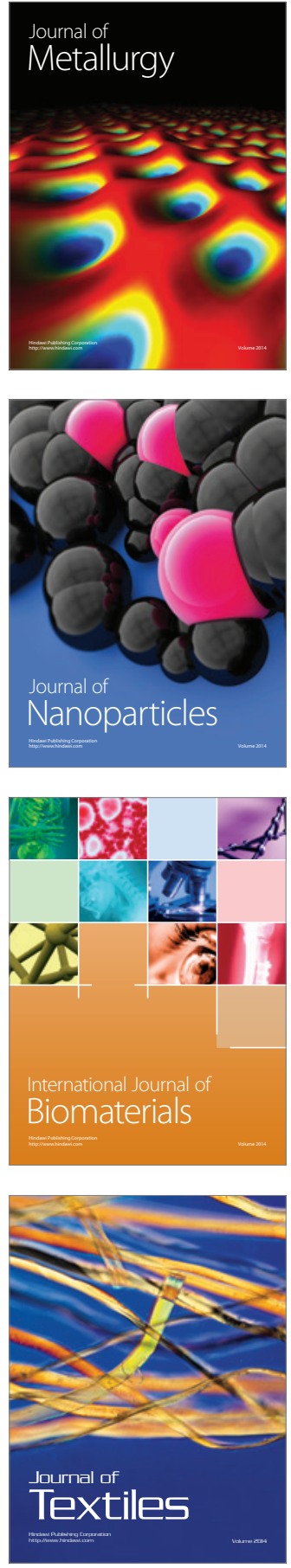